\title{
Mental Rotation Test Performance of Chinese Male and Female University Students
}

\author{
Ming Tsui ${ }^{1}$, Edmond Venator ${ }^{2}$, Xu Xiaoying ${ }^{3}$ \\ ${ }^{1}$ Department of Sociology-Anthropology, Millsaps College, Jackson, Mississippi, USA \\ ${ }^{2}$ Department of Psychology, Millsaps College, Jackson, Mississippi, USA \\ ${ }^{3}$ Department of Physics, Wuhan University of Technology, Wuhan, China \\ Email: tsuim@millsaps.edu, even43r@gmail.com, xu xiao ying@126.com
}

Received 12 February 2014; revised 15 March 2014; accepted 27 March 2014

Copyright (C) 2014 by authors and Scientific Research Publishing Inc.

This work is licensed under the Creative Commons Attribution International License (CC BY). http://creativecommons.org/licenses/by/4.0/

(c) () Op Open Access

\section{Abstract}

The Mental Rotation Test (MRT) of spatial abilities has consistently produced large gender differences favoring males. Recent social changes in gender attitudes and gender roles have not diminished such differences. Of special interest is the finding that the MRT involves a spatial ability positively correlated with higher-level math ability; individuals who do well on the MRT also tend to score high on standardized test of mathematics. In our previous studies using a GRE Math Subject Practice Test, we had found a lack of gender differences in math for Chinese college students. At the same time, we found an over-representation of males among physics and computer sciences majors in Chinese colleges. These findings lead to an obvious question regarding gender differences in spatial ability, especially the MRT among Chinese students. The present study was conducted to obtain MRT data from the same population of Chinese college students used in our earlier math studies. We found male Chinese students scored significantly higher than their female counterparts on the MRT.

\section{Keywords}

Mental Rotation Test, MRT Test Performance, Chinese University Students

\section{Introduction}

The Mental Rotation Test (MRT) of spatial abilities (see Figure 1) has consistently produced large gender differences favoring males (Halpern, 2004; Linn \& Petersen, 1985; Masters \& Sanders, 1993; Voyer, Voyer, \& 

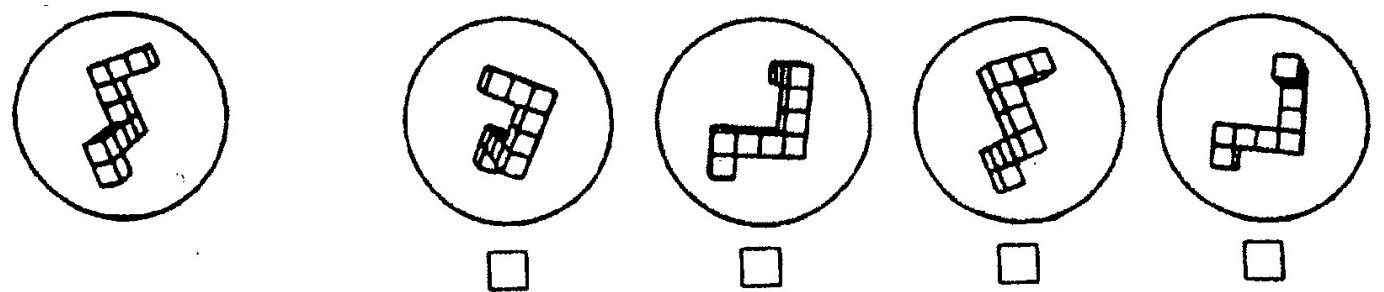

Figure 1. The Mental Rotation Test: The target figure is the one on the left. Testees are all required to mentally rotate each of the four figures at the right and put a check mark on the two that match the target (Vandenberg \& Kuse, 1978).

Bryden, 1995). In their 53-country cross-cultural study, Lippa, Collaer and Peters (2008) found universal gender differences in mental rotation with men's mean scores significantly higher than those obtained by women. While men and women in economically developed, gender-equal societies scored higher than their counterparts in gender-unequal, less-developed countries, larger gender differences on the MRT were also more likely to be found in gender-equal, developed countries.

While gender differences in spatial abilities are widely acknowledged, some scholars have argued that gender differences have been disappearing over time because of societal changes in gender attitudes and gender roles (Feingold, 1988; Rosenthal \& Rubin, 1982; Stumpf \& Klieme, 1989). However, a meta analysis (Masters \& Sanders, 1993) showed that gender differences on the MRT have remained stable since 1975. In another meta analysis covering nearly 50 years of research using various tests on spatial abilities, Voyer et al. (1995) found that gender differences did get smaller on some spatial-ability tests, but not on the MRT. In fact, they showed that the magnitude of the gender difference on the MRT had actually increased in recent years.

Goldstein, Haldane, and Mitchell (1990) hypothesized that the gender difference on the MRT is partly a function of performance factors related to response speed (women tend to work more slowly than men) and response style (women are more cautious than are men). In their experiments Goldstein and his colleagues found that while men obtained significantly higher raw scores under timed conditions, there were no significant gender differences when ratio scores (number of items correct divided by number attempted) were used or when unlimited time was given to complete the test.

Since then several MRT experiments using larger samples (Masters, 1998; Peters, 2005; Stumpf, 1993) have failed to replicate the findings of Goldstein et al. (1990). Masters (1998) allowed male and female college students either a short period or unlimited time on the MRT and used three different scoring methods to control for gender differences in number of questions attempted. "The results showed no evidence that the gender difference on the MRT was affected by the scoring method or the time limit” (Masters, 1998: p. 444). In Peter's 2005 study, although the overall scores obtained using a long time limit increased for both men and women, there was no significant reduction in the magnitude of gender differences.

Of special interest is the finding that the MRT involves a spatial ability positively correlated with higher-level math ability; individuals who do well on the MRT also tend to score high on standardized tests of mathematics (Casey et al., 1995; Gallagher, Levin, \& Cahalan, 2002; Goldstein et al., 1990; Peters et al., 2006). Casey et al.’s longitudinal research (1995) found that while male students outperformed female students on both the MRT and SAT-M for all their high-ability samples, "the male math advantage was reduced to nonsignificant levels for the college sample and the high ability college-bound students" when mental rotation skills were statistically adjusted for (Casey et al., 1995: p. 703). In the same study, Casey et al. (1995) also found that the mental rotation scores predicated math aptitude (performance on the SAT-M) for all female samples, but no consistent correlations were found for males. Studies conducted in Canada, Germany, and Japan (Peters et al., 1995; Peters et al., 2006)_found clear relationships between the MRT and college major; students, both males and females, majoring in math and sciences scored significantly higher on the MRT than their male and female counterparts in social sciences and humanities. However, within each academic program, males scored significantly higher than did females.

Several studies have related gender differences in mathematics to gender differences in spatial ability and argued that the male advantage at high levels of mathematics can be partly explained by a male advantage at visuospatial tasks (Benbow, 1988; Casey et al., 1995; Geary, 1999; Halpern, 2004). Dividing the quantitative questions on the GRE according to their cognitive attributes and solutions, Gallagher et al. (2002: p. 13) found 
that math problems "requiring generation of a spatial representation and manipulation of a given representation" showed the largest gender differences favoring males among the GRE test takers.

Using standardized math tests scores (the Chinese College Entrance Examination and a GRE Math Subject Practice Test), we have found a lack of gender differences in math for Chinese high school and college students (Tsui, 2007; Tsui \& Venator, 2008). At the same time, we found an over-representation of males in the science track in Chinese high-schools and an over-representation of males among physics and computer sciences majors in Chinese colleges. These findings lead to an obvious question regarding gender differences in spatial ability, especially the MRT among Chinese students. Geary and DeSoto (2001) found the typical males-better-than-females gender difference in MRT scores for Chinese college students. In their global study of gender differences in spatial ability, Lippa, Collaer, and Peters (2008) found that among the Chinese tested, men had higher MRT scores than did women. Here then is an apparent inconsistency: a lack of the typical gender difference in math coupled with the presence of a gender difference in spatial ability, a putative cause of the gender difference in math. However, the study of Geary and DeSoto (2001) was conducted in a Chinese normal college, while our studies revealing a lack of gender differences in math recruited physics majors at Wuhan University of Technology. Also, as reported by Lippa et al. (2008), their data have several limitations; the data were generated by a BBC internet study with an attendant lack of control over participants, and their MRT contained only six questions with instructions only in English. The present study was conducted to obtain MRT data from the same population of Chinese college students used in our earlier math studies (Tsui \& Venator, 2008).

\section{Method}

\subsection{Participants}

The participants were 202 sophomore physics majors (145 men and 57 women) at Wuhan University of Technology (WUT) in Wuhan, China. The gender disparity is consistent with the overall enrollment in physics at WUT.

\subsection{Materials}

The spatial test used was a redrawn version (MRT-A) of the original Mental Rotations Test (Vandenberg \& Kuse, 1978), provided by Dr. Michael Peters ${ }^{1}$ (Peters et al., 1995). The test consists of two sets of 12 items each, wherein each item consists of a three-dimensional target figure followed by two identical, but rotated, figures and two distracter figures (see Figure 1).

\subsection{Procedure}

The participants, tested at regularly scheduled meetings of their physics class, were given the following instructions.

Look at Page 1. Notice that the first five figures are all the same figure rotated around the vertical axis. Can you all see that all five versions are of the same figure? Look at the next two figures; they are different from the first five figures, but identical to each other.

Now look at the next group of figures. You see a target figure on the left and four stimulus figure on the right. In all problem sets there are two figures on the right which are rotated versions of the target figure, and two figures which cannot be made to match the target figure. In Problem set number 1, try to see which of the two figures are correct. The first and third figures match the target figure. You have to find both of the correct answers to get a point for a problem. A single correct answer or a correct and an incorrect answer do not count.

Now try three problems on page 2 . The correct answers are given below.

(After five minutes had elapsed, participants were told to turn over the test booklet with the face down.) We are ready to start when I say "begin". In each problem, remember there are two and only two correct solutions and you should mark these by putting an X through each correct figure (administrator illustrated). We will do pages 3 and 4, then take a little break. You will have 4 minutes for pages 3 and 4 . When I say stop turn the test face down immediately, even if you are in the middle of a problem.

Four minutes were allowed for each half of the test, with a five minute rest period between the first and

\footnotetext{
${ }^{1}$ We thank Dr. Peters for permission to use his redrawn version of the MRT.
} 
second half. ${ }^{2}$

As regards scoring, the original authors of the MRT (Vandenberg \& Kuse, 1978) recommended that one point be given for an item only if both correct options were selected, rather than awarding a point for each correct choice. We used the recommend scoring, therefore a perfect score would be 24 , as opposed to a perfect score of 48 produced by per-choice scoring.

\section{Results}

The mean number correct was 15.9 for the men and 12.1 for the women. An independent-groups analysis of variance revealed that the men earned significantly higher scores than the women, $\mathrm{F}(1,200)=20.872, p<0.0001$. The value Cohen's $\mathrm{d}$ for the gender difference is 0.73 , which is considered to be a moderate difference. There is significant negative skewness (skewness $=-0.61$, standard error $=0.201$ ) in the score distribution for men, at least a portion of which is likely related to the ceiling effect (see Figure 2).

\section{Discussion}

The gender difference on the MRT among physics majors at WUT is consistent with the earlier studies in China (Geary \& DeSoto, 2001; Lippa, Collaer, \& Peters, 2008) and the wealth of studies in other countries around the world. However, given that gender differences in spatial ability, especially on the MRT, have been related to gender differences in math performance, and we have found no differences in math performance among physics majors at WUT, the gender difference on the MRT at WUT is somewhat surprising.

To ensure an adequate level of difficulty, the math test we used with WUT physics majors (Tsui \& Venator, 2008) was composed of questions taken from a GRE-Math Subject Practice Test (Leduc, 2005), but at that time we were unaware of Gallagher's (1992) analysis of the relation between types of questions and gender differences. We gave two math professors the pages from the Gallagher (1992) article describing the characteristics of

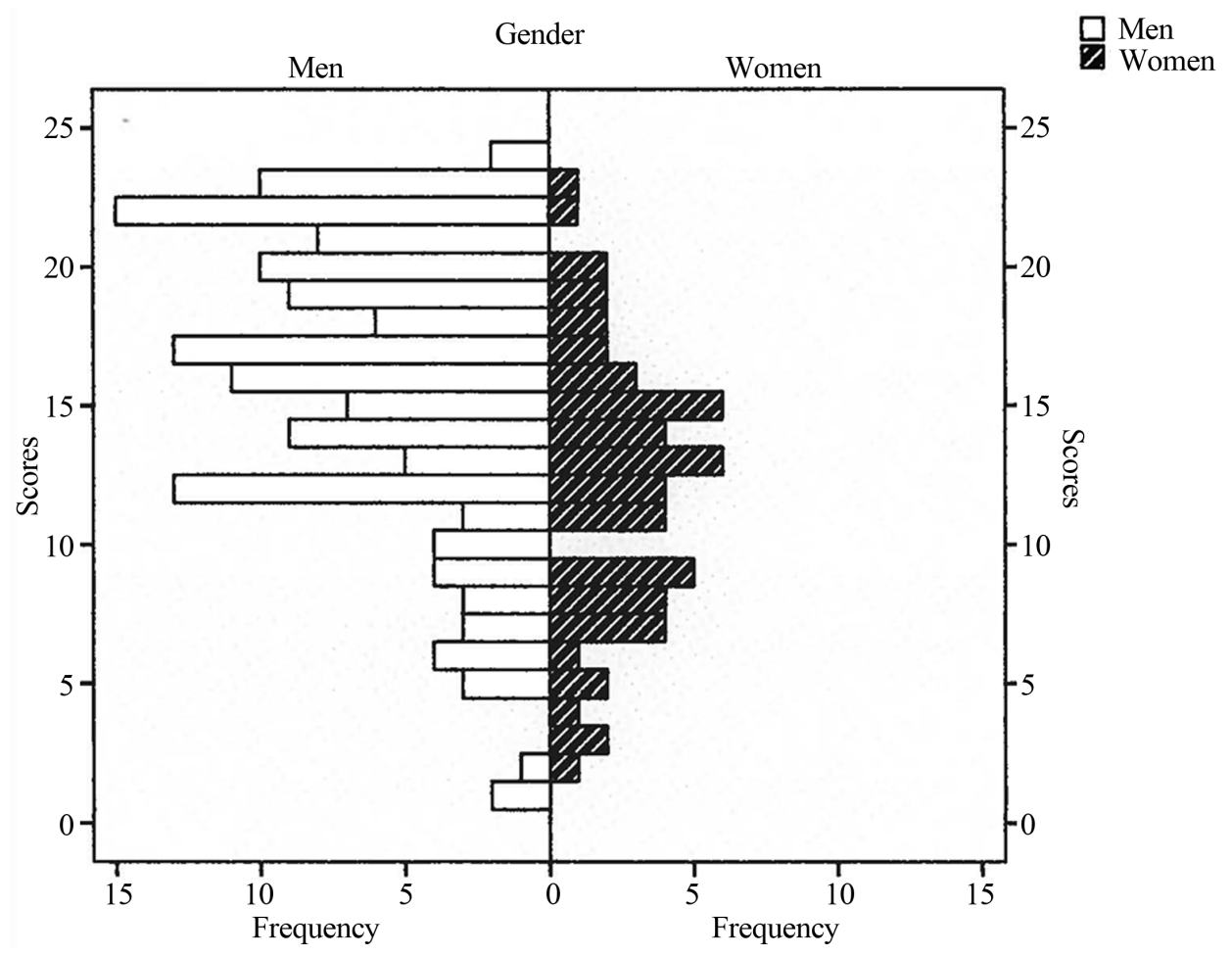

Figure 2. MRT scores as a function of gender.

\footnotetext{
${ }^{2}$ Though a variety of test times have been used, most recent studies have used 3 minutes for each half. In a technical report on the revised test, Peters (1995) stated that 4 minutes was acceptable. We used four rather than three minutes because this type of testing is rare in Chinese universities and we thought more time would be desirable. We were wrong; three of the boys achieved perfect scores of 24 yielding a ceiling effect in our data.
} 
the four different types of questions and a copy of the test we had been using in China and asked them to classify the question on our test. Both reported that our test questions were all of Type I, the type for which males do not score higher than females.

We have now constructed a new test with questions taken from a recently released GRE Advanced Math Test. $^{3}$ This new twenty-item test contains ten Type I items and ten items of Types II, III, and IV. Types II, III, IV, which collectively comprise about half of the GRE Advanced Math Test, are the types of questions on which men score higher than women (Gallagher, 1992). This new test has been administrated to physics majors at the WUT and we are currently analyzing the results.

\section{References}

Benbow, C. P. (1988). Sex Differences in Mathematical Reasoning Ability in Intellectually Talented Preadolescents: Their Nature, Effects, and Possible Causes. Behavioral and Brain Sciences, 11, 169-232.

http://dx.doi.org/10.1017/S0140525X00049244

Casey, M. B., Nuttall, R., Pezaris, E., \& Benbow, C. P. (1995). The Influence of Spatial Ability on Gender Differences in Mathematics College Entrance Test Scores across Diverse Samples. Developmental Psychology, 31, 697-705. http://dx.doi.org/10.1037/0012-1649.31.4.697

Feingold, A. (1988). Cognitive Gender Differences Are Disappearing. American Psychologist, 43, 95-103. http://dx.doi.org/10.1037/0003-066X.43.2.95

Gallagher, A. (1992). Sex Differences in Problem-Solving Strategies Used by High-Scoring Examinees on the SAT-M. The College Board Report No. 92-2, The College Board.

Gallagher, A., Levin, J., \& Cahalan, C. (2002). Cognitive Patterns of Gender Differences on Mathematics Admissions Tests. GRE Board Professional Report No. 96-17, Princeton, NJ: Educational Testing Service.

Geary, D. (1999). Sex Differences in Mathematical Abilities: Commentary on the Math-Fact Retrieval Hypothesis. Contemporary Educational Psychology, 24, 267-274. http://dx.doi.org/10.1006/ceps.1999.1007

Geary, D., \& DeSoto, M. C. (2001). Sex Differences in Spatial Abilities among Adults from the United States and China: Implications for Evolutionary Theory. Evolution and Cognition, 7, 172-177.

Goldstein, D., Haldane, D., \& Mitchell, C. (1990). Sex Differences in Visual-Spatial Ability: The Role of Performance Factors. Memory and Cognition, 18, 546-550. http://dx.doi.org/10.3758/BF03198487

Halpern, D. F. (2004). A Cognitive-Process Taxonomy for Sex Differences in Cognitive Abilities. Current Directions in Psychological Science, 13, 135-139. http://dx.doi.org/10.1111/j.0963-7214.2004.00292.x

Leduc, S. (2005). Cracking the GRE Math Subject Test. The Princeton Review, New York: Random House.

Linn, M., \& Petersen, A. (1985). Emergence and Characterization of Sex Differences in Spatial Ability: A Meta-Analysis. Child Development, 56, 1479-1498. http://dx.doi.org/10.2307/1130467

Lippa, R. A., Collaer, M. L., \& Peters, M. (2010). Sex Differences in Mental Rotation and Line Angle Judgment Are Positively Associated with Gender Equality and Economic Development across 53 Nations. Archaeology of Sex Behavior, 39, 990-997.

Masters, M. (1998). The Gender Difference on the Mental Rotations Test Is Not Due to Performance Factors. Memory \& Cognition, 26, 444-448. http://dx.doi.org/10.3758/BF03201154

Masters, M., \& Sanders, B. (1993). Is the Gender Difference in Mental Rotation Disappearing? Behavior Genetics, 23, 337341. http://dx.doi.org/10.1007/BF01067434

Peters, M. (2005). Sex Differences and the Factor of Time in Solving Vandenberg and Kuse Mental Rotation Problem. Brain and Cognition, 57, 176-184. http://dx.doi.org/10.1016/j.bandc.2004.08.052

Peters, M., Lehmann, W., Takahira, S., Takeuchi, Y., \& Jordan, K. (2006). Mental Rotation Test Performance in Four CrossCultural Samples (N=3367): Overall Sex Differences and the Role of Academic Program in Performance. Cortex, 42, 1005-1014. http://dx.doi.org/10.1016/S0010-9452(08)70206-5

Peters, M., Laeng, B., Latham, K., Jackson, M., Zaiyouna, R., \& Richardson, C. (1995). A Redrawn Vandenberg and Kuse Mental Rotations Test: Different Versions and Factors That Affect Performance. Brian and Cognition, 28, 39-58. http://dx.doi.org/10.1006/brcg.1995.1032

Rosenthal, R., \& Rubin, D. (1982). Further Meta-Analytic Procedures for Assessing Cognitive Gender Differences. Journal of Educational Psychology, 74, 708-712. http://dx.doi.org/10.1037/0022-0663.74.5.708

\footnotetext{
${ }^{3}$ We thank ETS for its permission to use part of the GRE Math Subject questions for our research.
} 
Stumpf, H. (1993). Performance Factors and Gender-Related Differences in Spatial Ability: Another Assessment. Memory \& Cognition, 21, 828-836. http://dx.doi.org/10.3758/BF03202750

Stumpf, H., \& Klieme, E. (1989). Sex-Related Differences in Spatial Ability: More Evidence for Convergence. Perceptual \& Motor Skills, 69, 915-921. http://dx.doi.org/10.2466/pms.1989.69.3.915

Tsui, M. (2007). Gender Differences in Mathematics and Sciences Achievement in China and the United States. Gender Issues, 21, 1-11. http://dx.doi.org/10.1007/s12147-007-9044-2

Tsui, M., \& Venator, E. (2008) Stereotype Threat and the Academic Performance of Chinese Students (in Chinese). Society: Chinese Journal of Sociology (in Chinese), 28,191-202.

Vandenberg, S., \& Kuse, A. (1978). Mental Rotation, a Group Test of Three-Dimensional Spatial Visualization. Perceptual and Motor Skills, 47, 599-604. http://dx.doi.org/10.2466/pms.1978.47.2.599

Voyer, D., Yoyer, S., \& Bryden, M. P. (1995). Magnitude of Sex Differences in Spatial Abilities: A Meta-Analysis and Consideration of Critical Variables. Psychological Bulletin, 117, 250-270. http://dx.doi.org/10.2466/pms.1978.47.2.599 